Supplementary Information for

\title{
High performance metal oxide field-effect transistors with reverse offset printed $\mathrm{Cu}$ source/drain electrode
}

Young Hun Han ${ }^{l}$, Ju-Yeon Won ${ }^{1}$, Hyun-Seok Yoo ${ }^{2}$,Jae-Hyun Kim ${ }^{2}$, Rino Choi ${ }^{l}$ and Jae Kyeong Jeong $^{3 *}$

${ }^{1}$ Department of Materials Science and Engineering, Inha University, Incheon 402-751, South Korea

${ }^{2}$ Advanced Research Institute, Dongjin Semichem Co. Ltd., Gyeonggi 463-400, South Korea

${ }^{3}$ Department of Electronic Engineering, Hanyang University, Seoul 133-791, South Korea

AUTHOR EMAIL ADDRESS: J. K. Jeong (jkjeong1@hanyang.ac.kr)

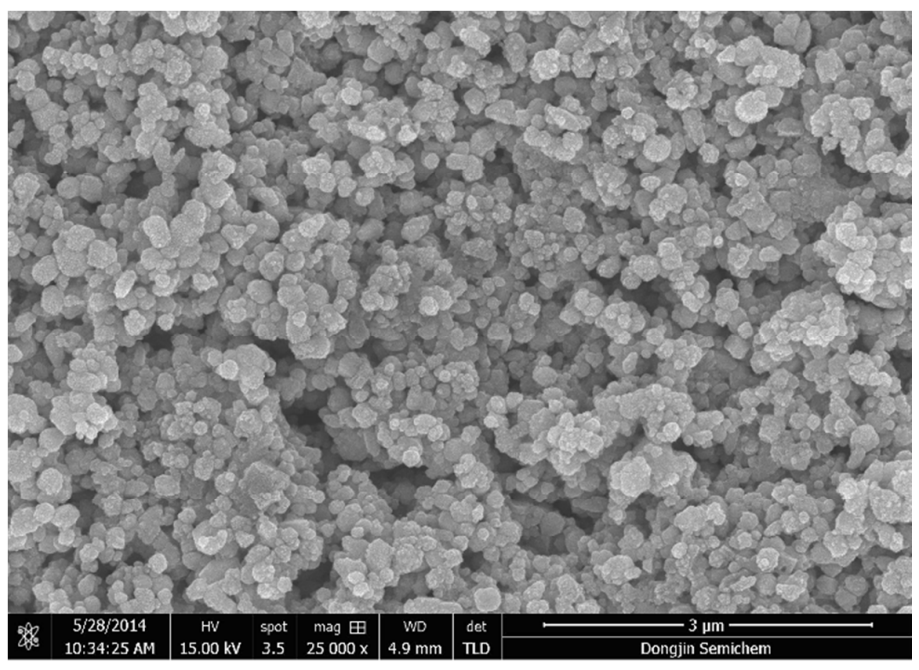

Figure S1. SEM image of $\mathrm{Cu}$ nanoparticles for the formulation of $\mathrm{Cu}$ ink. 


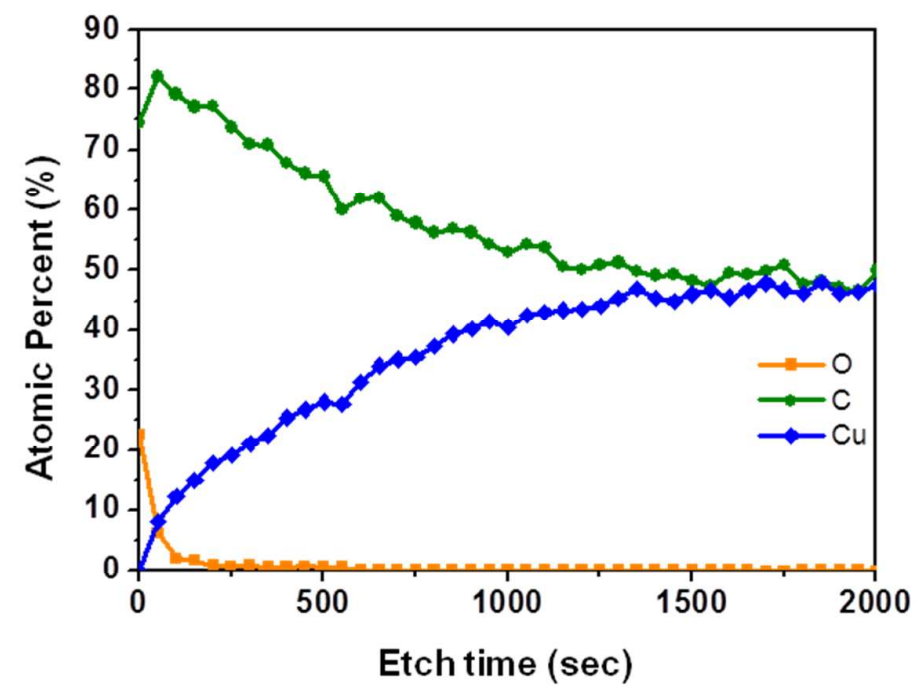

Figure S2. Concentration depth profiles for $\mathrm{Cu}, \mathrm{O}$ and $\mathrm{C}$ obtained by XPS for the $\mathrm{Cu}$ green-body film dried at $200{ }^{\circ} \mathrm{C}$ for $30 \mathrm{sec}$ in air. 

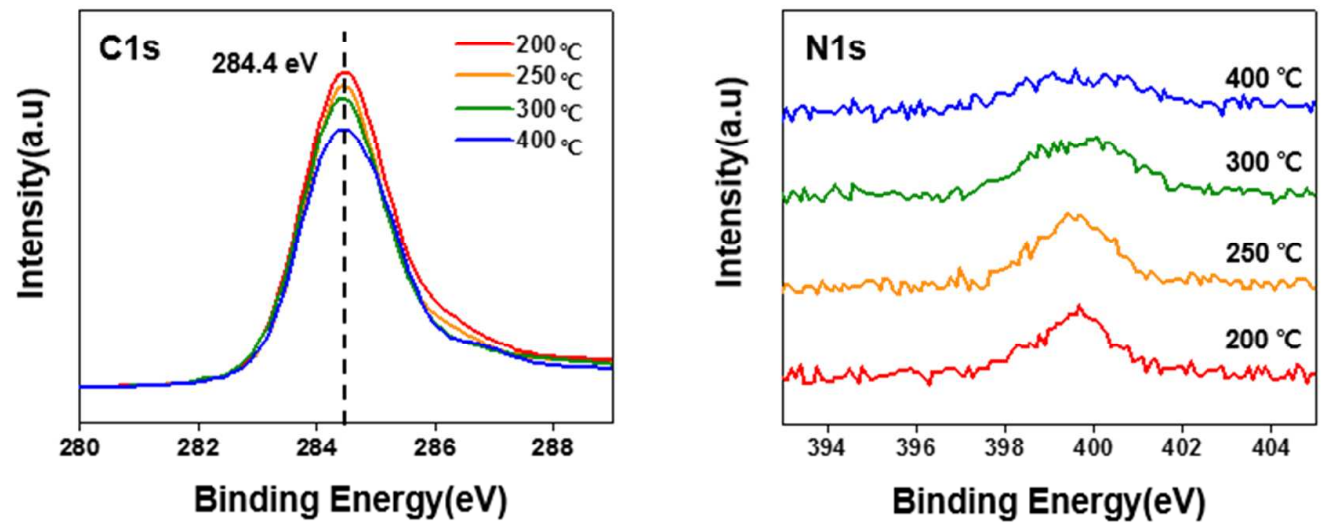

Figure S3. C $1 s$ and $\mathrm{N} 1 s \mathrm{XP}$ spectra for the different $\mathrm{Cu}$ films.
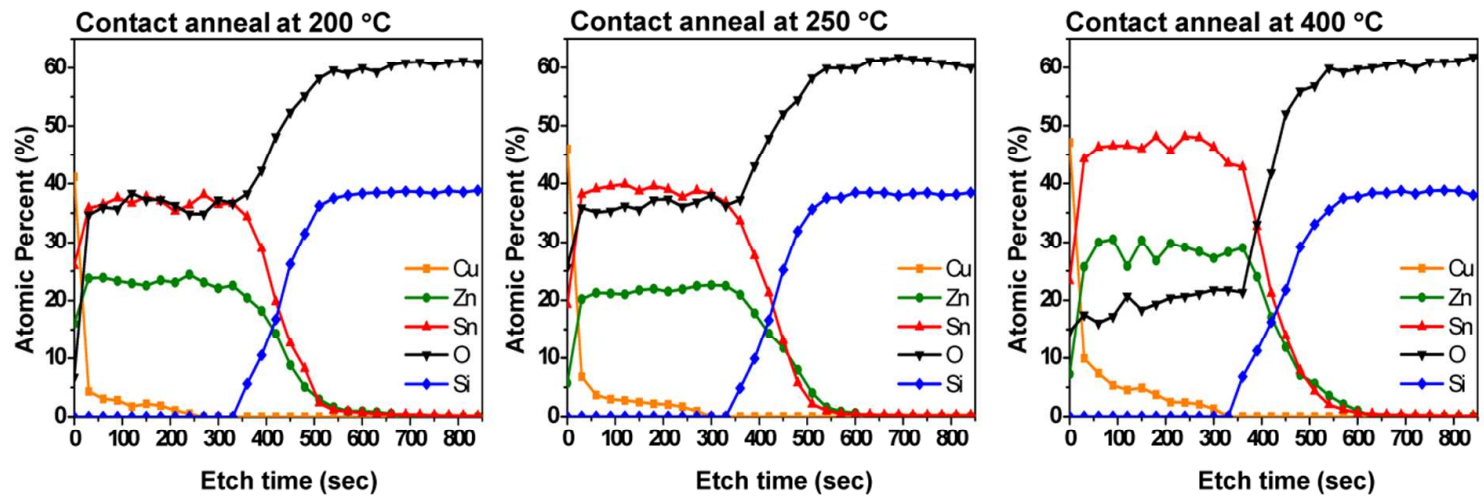

Figure S4. Concentration depth profiles for $\mathrm{Cu}, \mathrm{Zn}, \mathrm{Sn}$ and $\mathrm{O}$ obtained by XPS for the $\mathrm{Cu}$ films on the $\mathrm{ZTO} / \mathrm{SiO}_{2} / \mathrm{Si}$ substrates as a function of the contact annealing temperatures under $\mathrm{N}_{2}$ atmosphere. The zero etch time corresponds to the interface between the $\mathrm{Cu}$ film and ZTO channel layer. 
Table S1. Electrical characteristics of the ZTO FETs with the sputtered ITO S/D electrode under different contact anneal conditions.

\begin{tabular}{|c|c|c|c|c|c|c|}
\hline & \multicolumn{6}{|c|}{ Different contact anneal conditions (temperature/atmosphere) } \\
\hline & $\begin{array}{c}250{ }^{\circ} \mathrm{C} \\
\text { air }\end{array}$ & $\begin{array}{c}250{ }^{\circ} \mathrm{C} \\
\mathrm{N}_{2}\end{array}$ & $\begin{array}{c}400^{\circ} \mathrm{C} \\
\text { air }\end{array}$ & $\begin{array}{c}400{ }^{\circ} \mathrm{C} \\
\mathrm{N}_{2}\end{array}$ & $\begin{array}{c}500^{\circ} \mathrm{C} \\
\text { air }\end{array}$ & $\begin{array}{c}500^{\circ} \mathrm{C} \\
\mathrm{N}_{2} \\
\end{array}$ \\
\hline$\mu_{\mathrm{FET}} \quad\left[\mathrm{cm}^{2} \mathrm{~V}^{-1} \mathrm{~s}^{-1}\right]$ & 4.8 & 5.4 & 4.9 & - & 4.9 & - \\
\hline SS $\left[V_{\text {decade }}^{-1}\right]$ & 0.54 & 1.06 & 0.50 & - & 0.30 & - \\
\hline$V_{\text {th }}[\mathrm{V}]$ & 2.3 & 2.5 & 2.4 & - & 2.6 & - \\
\hline
\end{tabular}

